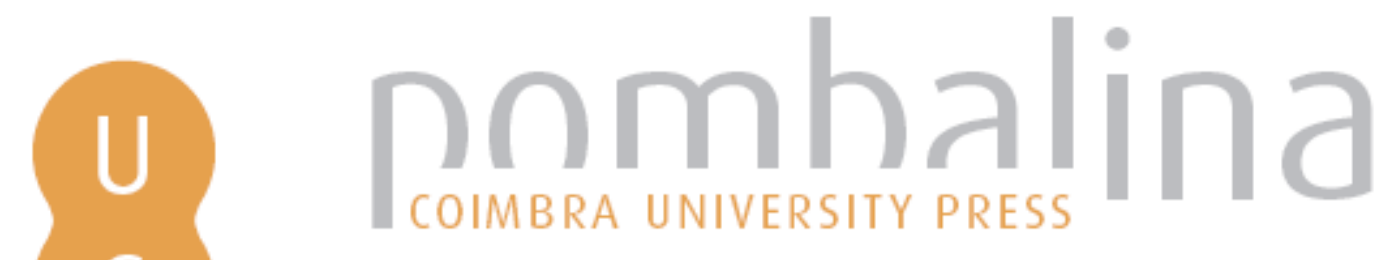

\title{
O Auto da Festa e a (rica) Oficina de Gil Vicente
}
Autor(es): $\quad$ Bernardes, José Augusto Cardoso
Publicado por: Imprensa da Universidade de Coimbra
URL
persistente: URI:http://hdl.handle.net/10316.2/38690
DOI: $\quad$ DOI:http://dx.doi.org/10.14195/978-989-26-1164-8_13
Accessed : $\quad$ 26-Apr-2023 13:48:58

A navegação consulta e descarregamento dos títulos inseridos nas Bibliotecas Digitais UC Digitalis, UC Pombalina e UC Impactum, pressupõem a aceitação plena e sem reservas dos Termos e Condições de Uso destas Bibliotecas Digitais, disponíveis em https://digitalis.uc.pt/pt-pt/termos.

Conforme exposto nos referidos Termos e Condições de Uso, o descarregamento de títulos de acesso restrito requer uma licença válida de autorização devendo o utilizador aceder ao(s) documento(s) a partir de um endereço de IP da instituição detentora da supramencionada licença.

Ao utilizador é apenas permitido o descarregamento para uso pessoal, pelo que o emprego do(s) título(s) descarregado(s) para outro fim, designadamente comercial, carece de autorização do respetivo autor ou editor da obra.

Na medida em que todas as obras da UC Digitalis se encontram protegidas pelo Código do Direito de Autor e Direitos Conexos e demais legislação aplicável, toda a cópia, parcial ou total, deste documento, nos casos em que é legalmente admitida, deverá conter ou fazer-se acompanhar por este aviso.

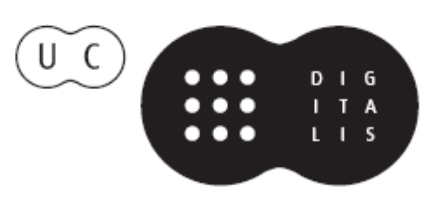


José Augusto Cardoso Bernardes

Universidade de Coimbra / Centro de Literatura Portuguesa

\section{O AUTO DA FESTA}

\section{E A (RICA) OFICINA DE GIL VICENTE}

\section{A descoberta}

O Auto da Festa foi revelado em 1906, saindo do anonimato de uma biblioteca privada (o Palácio do Calvário), onde figurava em miscelânea de textos impressos ao longo da segunda metade do século xvi e inícios do xvir ${ }^{1}$. Tratava-se de uma série de 21 obras, correspondendo, na sua maioria, a textos dramáticos de Quinhentos, em boa parte desconhecidos. A ocasião era propícia para revelações deste tipo. Lembremo-nos de que ainda não tinha decorrido um século sobre a edição de Hamburgo (publicada em três volumes, no ano de 1834), que, como sabemos, equivalia a uma verdadeira e espectacular ressurreição de Gil Vicente $^{2}$. Ainda na sequência dessa ressurreição, tinham-se comemorado, quatro anos antes, com significativo impacto público, os 400 anos da representação do

\footnotetext{
1 Trata-se de um volume in $-4^{\circ}$, encadernado em bezerro, tendo na lombada, a ouro a seguinte indicação. "Varias crusid. Tom-III". Para além de outros textos, (de carácter lírico, como as famosíssimas "Coplas a morte de su padre", de Jorge Manrique), na citada miscelânea encontram-se ainda textos de dramaturgos como Ribeiro Chiado, Fernando Mendes, Afonso Álvares e Baltasar Dias. Os autos de Gil Vicente que figuram na citada miscelânea são, para além de Festa, Fé, Breve Sumário, Cananeia, Barca do Inferno. Assinale-se, por fim, a presença de duas peças de autoria duvidosa: Deus Padre e Geração Humana.

2 O próprio descobridor do auto alude, deste modo, a essas mesmas circunstâncias: "a atmosphera criada na Europa culta e no Brasil por esse grupo de lusophilos (alude a D. Carolina M. de Vasconcelos, Alexandre Herculano, Gama Barros e Teophilo Braga) contribuiu eficazmente para ser seguido com sympathia o movimento neo-vicentino, que se manifestou com a celebração do quarto centenário (...) e decerto favorecerá o acolhimento da publicação deste Auto, que vem trazer ao thesouro da litteratura uma perdida jóia e não das menos valiosas" (cf. p. 519).
} 
Monólogo do Vaqueiro ${ }^{3}$. Mas, para compreendermos o sentido de oportunidade deste acontecimento precisamos sobretudo de nos lembrar de que estávamos em tempo de exaltação filológica, envolvendo uma grande recetividade a tudo o que pudesse significar um acrescento ao património muito especial que eram, em Portugal, as Letras quinhentistas.

O possuidor da dita miscelânea era o Conde de Sabugosa, figura prestigiada de aristocrata e de polígrafo. Só assim se entende o zelo colocado por ele na edição. De facto, para além de ter transcrito o texto com assinalável escrúpulo, o editor assinou ainda um longo estudo introdutório, que reflete os atributos essenciais da Filologia da época: clareza, fundamentação e prudência.

Nesse estudo não se iludem, desde logo, as questões mais intrigantes, que, como veremos, chegaram até aos nossos dias. Não se sabia, por exemplo (e não se sabe ainda) por que motivo o auto não chegou a figurar em nenhuma das duas edições quinhentistas da Compilação de Gil Vicente. São várias as hipóteses de explicação (acidental e essencial) e algumas delas foram, desde logo, suscitadas pelo Conde: tê-lo-ia rejeitado o próprio Gil Vicente? Teria a rejeição partido dos filhos que lhe editaram a obra postumamente? Nesse caso, cumpre ainda perguntar por que razão teria a peça sido objeto de censura particular? A todas estas razões "externas" acrescia ainda uma outra, de natureza "interna": resultará o presente auto de uma pura colagem de cenas, efetuada à revelia da vontade do autor e quase seguramente depois da sua morte?

Há que reconhecer que qualquer destas hipóteses detém uma boa margem de verosimilhança. Pelo menos, até hoje, ainda não se descobriu nada que certifique definitivamente uma delas com exclusão das outras. De facto, o texto contém materiais (personagens, situações, frases) que encontramos em outros autos; e talvez isso fosse suficiente para que o dramaturgo tivesse renunciado a incluí-lo na edição global que, tudo o indica, chegou a ter em adiantado estado

\footnotetext{
3 Contendo numerosos lapsos, a edição de Hamburgo, levada a efeito por Gomes Monteiro e Mascarenhas Barreto, teve, no entanto, circulação limitada. Como se isso não bastasse, por via de um incêndio no Depósito, o livro cedo se tornou numa relativa raridade. Nessas circunstâncias, a edição de 1852, que integrou a prestigiada colecção "Bibliotheca Portuguesa", viria a constituir um acontecimento importante para a afirmação canónica da obra vicentina, em Portugal e no Brasil.

4 No termo da sua aproximação ao auto, Pratt emite este juízo taxativo: “... curioso, embora pelo estudo de costumes e tipos de tempos que aliás não acrescentam novos aspectos às telas vicentinas, é talvez a menos cuidada de todas as produções do poeta" (Cf. p. 235). Na seriação que leva a efeito, Osório Mateus exclui mesmo o Auto, num gesto que parece significar a negação de autoria vicentina (Livro das Obras, Lisboa, Quimera, 1993).
} 
de preparação. Mas os motivos do expurgo podem ter sido de natureza bem diferente. De facto, mesmo descontando o elevado grau de impunidade de que Gil Vicente por certo beneficiaria, não pode iludir-se que a peça contém matéria potencialmente escandalosa. Não esqueçamos que, logo a abrir, a Verdade se confessa escorraçada da Corte portuguesa, sugerindo que nessa rejeição possa ter havido conivência ou passividade do próprio Rei:

Oh grã crueldade

Que o tempo de agora tem tal calidade

Que cedo no paço já trazem por Lei

Que todo aquele que falar verdade

É logo botado da graça d'el rei. (p. 656)5

Mesmo ausente, o monarca é assim convocado de várias formas. Repare-se, desde logo, que a personagem se dirige a um determinado Senhor em termos que o distinguem e o colocam acima do próprio soberano. Depois de ter dito o que disse da sua má relação com ele, a Verdade refere-se agora ao misterioso Senhor em cuja casa se apresenta, indo além do encómio de circunstância e tomando-o, na prática, como um protetor alternativo:

E tendo sabido que vós, meu senhor,

Me tendes amizade e fé verdadeira,

E por isso venho de aquesta maneira

Dar-vos as graças por tão grande amor.

E com pensamento

De em vossa pousada fazer aposento,

Pois me amais com tanta firmeza,

De vossa boca farei fortaleza

Para estar nela sempre de assento. (pp. 656-57)

A estes motivos, que podemos identificar como sendo de grave escândalo político, juntam-se ainda outros, de natureza moral. Basta lembrarmo-nos do

\footnotetext{
5 As citações do auto têm por base a transcrição feita por José Camões no Vol. II das Obras.
} 
primeiro vilão (João Antão, original da Beira), aludindo desbragadamente ao ato sexual que, num determinado domingo, praticou com a mulher do juiz (logo ela). O tópico do rústico que dorme com uma mulher comprometida e de condição superior é relativamente frequente nas farsas medievais. Ainda assim, há que admitir que os contextos farsescos eram normalmente mais vagos, reenviando para a comunidade popular e urbana e para a maior permissividade de linguagens e costumes que nela prevalecia. Como facilmente se compreende, em contexto palaciano, uma alusão destas poderia ser de todo inconveniente, tanto no plano abstrato como no diz respeito às referências pessoais que o caso poderia trazer a lume.

\section{As circunstâncias de representação}

As indeterminações invocadas poderiam esclarecer-se através de um fator que, noutros autos vicentinos, se revela muito útil. Refiro-me às circunstâncias de representação. Mas tal não sucede desta vez. Não sabemos, de facto, quando e perante quem foi representado o auto. Com argumentos plausíveis, e seguindo Óscar de Pratt, José Camões (um dos poucos vicentistas vivos que se ocupou do auto) localiza-o num Natal posterior ao ano de 1526, mantendo também dúvidas sensatas sobre a identidade dos destinatários imediatos da representação: ao que tudo indica, a peça terá, de facto, sido representada perante uma corte senhorial, o que, desde logo, parece conferir à peça um estatuto de relativa excecionalidade ${ }^{6}$.

No seu estudo, o Conde de Sabugosa atribuíra mesmo consequências práticas a este facto, assinalando que talvez estivesse aí a explicação para um possível extravio do texto:

\footnotetext{
6 "É dos poucos autos, tal como Tormenta e Cananea, que não terão sido representados para a Corte. No entanto, há palavras de figuras de auto que apontam para uma representação em espaço régio: "vim-me à corte" (1'24), vós outros que andais no paço". Se esta última expressão não exclui outros espaços, a verdade é que, pelo menos, aponta para um público pação (...). Janafonso refere o espaço como "sagrado" e" moesteiro". (Camões, p. 3).
} 
...foi talvez a circumstancia de não ter nascido na atmosphera ruidosa da Côrte de o original não ter sido guardado nas arcas da câmara que mais depressa o lançaria no esquecimento. (p. 67).

Procurando ser mais concreto, o mesmo estudioso sustentara que a peça pode ter sido representada em Évora, no Natal de 1535 , perante o $1^{\circ}$ Conde de Vimioso, D. Francisco de Portugal. Em socorro da sua tese, o Conde chama a atenção para a semelhança (realmente indesmentível) que se verifica entre o elogio que a Verdade dirige ao destinatário e as palavras que Gil Vicente coloca na boca da mesma personagem durante a Aclamação de D. João III (Camões, p. 87).

\section{Os procedimentos oficinais}

Mais importante, porém, do que saber se estamos perante uma peça esquecida, enjeitada ou proibida (as três possibilidades podem, perfeitamente, convergir e ser complementares) justifica-se tentar saber até que ponto a análise do texto se revela útil para captar a criação vicentina "em processo". Com efeito, se repararmos bem, e não havendo praticamente dúvidas sobre a autoria da obra, estamos perante uma produção vicentina que alguém decidiu que não deveria figurar na Copilaçam: o próprio autor ou os filhos. Sejam quais forem os motivos que conduziram a essa decisão, é muito provável que o texto de que hoje dispomos possa dizer-nos coisas novas sobre a forma como funcionava a oficina do dramaturgo. Tentemos, pois, fazer-lhe as perguntas que se impõem.

Como tem sido notado, desde 1906, o auto pode realmente ser visto como uma espécie de mosaico de parte significativa do teatro vicentino: à semelhança do que sucede com a pequena farsa homónima, temos, em Festa, ciganas que exibem dotes de adivinhação; como na Barca do Inferno, Juiz da Beira ou Floresta de Enganos, critica-se o funcionamento da Justiça (desta vez é a Verdade que assinala a João Antão a necessidade de "comprar", com perdizes, um bom despacho do juiz); por seu turno, seguindo as pisadas de Pero Marques, (o nosso bem conhecido marido de Inês Pereira e Juiz da Beira), o mesmo rústico contrapõe

7 Como bem notou Eneida Bonfim, as ciganas de Festa são menos corteses (ou mais grosseiras) do que a farsa vicentina do mesmo nome (Cf. pp. 200 e ss.). 
à justiça dos códigos aquela que resulta da própria natureza: se a mulher do juiz esteve de acordo e folgou com a relação que mantiveram, porque há-de ele ser condenado? ${ }^{8}$ Também temos um Parvo que, por sinal, se revela, ao mesmo tempo, evangélico e obsceno, lembrando, nessa duplicidade, o Joane, da Barca do Inferno; em Festa, o Parvo chega a propor casamento à Verdade, que não se mostra agastada com a proposta; ora, essa cumplicidade traz à memória a garantia do Céu dada a Joane pelo Anjo na primeira Barca. Um segundo vilão (Janafonso, que vem de Bragança) quer pedir ao Deus nascido que o case, não aceitando, desde logo, que Ele o não receba:
Ca se Deus fosse ocupado
Como homem diz a respeito,
Mas ele tem tudo feito
Dantes que ele fosse nado
E meu visavô desfeito. (p. 668)

Outra afinidade entre os dois Parvos resulta do facto de, também neste caso, ele permanecer em cena, mesmo depois de obtido o seu "despacho". Enquanto na Barca do Inferno, Joane fica do lado do Anjo, também aqui o Parvo fica junto à Verdade, dialogando com Janafonso e com a Velha Filipa Pimenta (sua mãe). A cena final, envolvendo a celebração do casamento entre a Velha e o pastor Gil Tibabo, traz à memória uma situação idêntica ocorrida na Farsa de Inês Pereira (versão da folha volante), que ali se desenvolve, em torno do casamento de Inês com o Escudeiro Brás da Mata.

Mas, embora talvez de forma menos evidente, os paralelismos podem continuar: na sua sandice amorosa, a velha Filipa Pimenta lembra muito a Brásia Caiada do Triunfo do Inverno: uma e outra representam a subversão grotesca da Natureza e estão dispostas a todos os sacrifícios para cumprirem as suas ânsias tardias. Um outro tópico comum é o que relaciona os castigos de Deus ("que é verdade acabada") com a fuga à Verdade: recorde-se que essa mesma lógica punitiva se aplica a todo o Auto da Feira e, em particular, à personagem de Roma, castigada

8 Para uma meticulosa comparação entre o Janafonso de Festa e o vilão do Templo de Apolo, veja-se o já citado estudo de Eneida Bonfim. 
pela Providência, por ter pactuado com o Diabo; a semelhança entre os dois autos pode finalmente notar-se na cena que precede imediatamente o aparato do Presépio: refiro-me ao grupo de nove pastores devotos da Virgem, mostrando-se especialmente recetivos aos Seus dons e situando-se nos antípodas de todos os que cultivam as aparências enganosas, em detrimento das essências verdadeiras (Roma, compadres e comadres). Tal como em Feira, também Festa termina com um grupo de pastores (neste caso, um rapaz e três moças) que, a pretexto das núpcias, celebram o Natal e a Verdade. Deve aliás, fazer-se notar que esta cena, de índole estritamente teatral, não aparece na versão mais literária da Copilaçam.

Em face do que fica dito, é grande a tentação de pensar que estamos perante um auto realmente "repetido" e, por isso, "dispensável". Decerto seria esse o efeito do Auto no leitor comum (aquele que Gil Vicente ou os filhos tinham em vista ao coligirem o Livro das Obras). Não é assim, contudo, para o leitor mais exigente. Para esse tipo de leitor, justamente porque inclui ecos e prenúncios de muitos outros, o Auto pode também ser encarado sob o ponto de vista oficinal.

A própria circunstância de estarmos perante um extenso repositório de fórmulas teatrais, faz pensar que nos encontramos perante uma situação única no conjunto da produção vicentina que chegou até nós. Se retirarmos o caso muito particular das Barcas e das personagens sacras, angélicas e diabólicas que evoluem nas moralidades, a presença de uma mesma personagem em mais do que um auto é muito rara (Pero Marques e Inês Pereira constituem casos isolados ao longo de toda a Compilação).

Mas, com todas as repetições que costumam assinalar-se, não pode esquecer-se que existe em Festa uma novidade importante. Refiro-me, naturalmente à presença da Verdade, alegoria ordenadora que não figura em nenhuma outra peça vicentina. É ela que abre o auto, num Prólogo que, só por si, constitui uma Pregação completa e concatenada sobre o desconcerto do mundo e da Corte portuguesa, em particular; é ainda ela quem, depois, preside ao desfile dos romeiros, assegurando a ligação entre as diferentes cenas. O destaque que lhe é concedido surge, desde logo, assinalado sob o ponto de vista formal: com efeito, a Verdade é a única personagem que se exprime em versos de arte maior, em consonância com o registo persuasivo e declamatório do seu discurso. Deve dizer-se que a situação corresponde, de resto, a um expediente muito comum no teatro medieval: cometer a uma personagem fixa a função de ligar os elementos 
móveis de toda a peça (tal como sucede em Agravados, Templo de Apolo, Cortes de Júpiter ou Barcas). Mas não se trata apenas disso. Para além da componente teatral, a Verdade cumpre ainda outra função: em dia de Natal, toma verdadeiramente o papel do Presépio, assumindo-se como foco ou lastro de sentido; fala de si própria mas, ao mesmo tempo, leva todas as outras personagens a confrontarem-se com a sua presença. Nessa medida, para além de valer pelo que representa, a Verdade faz com que todas as figuras que chegam (e regressam) valham também pela sua relação com a figura que tomou assento naquele lugar, dominando a cena, mesmo quando não intervém expressamente. Na sua dimensão axiológica, pode afinal dizer-se que a personagem ocupa o lugar que noutros autos vicentinos de Natal é ocupado por Cristo ou pela Virgem.

Já tive ocasião de notar que as lamentações da Verdade são bem incisivas: o desprezo a que é votada por todo o lado, incluindo a Corte, chega a fazer dela uma figura lírica, atributo direto do campo do Bem. É isso que explica que se afirme como filha direta da Santíssima Trindade, em contiguidade evidente com a Fé. A própria circunstância de, depois de expulsa de outros lugares, se dirigir a um determinado senhor, na suposição de nele ainda poder encontrar guarida, leva a que indiretamente se torne também filha da Esperança. De tal forma a alegoria se torna central que bem pode dizer-se que Gil Vicente reúne nela os dois pilares estéticos que sustentam toda a sua obra: Sátira e Lirismo. De facto, tanto é possível sublinhar a crítica moral que atinge o mundo (por se alhear da Verdade) como se torna fácil detetar, através dos seus apelos morais e da sua afinidade com o Parvo, a pregação dos valores da humildade e da justiça, que tantas vezes, nos sermonários da época, funcionam como opostos radicais da mentira.

Definida desta forma, a alegoria de que venho falando não é válida apenas para este auto, podendo admitir-se um processo de irradiação que toca toda a obra de Gil Vicente: no fundo, esta Verdade é a mesma que é submetida a prova no Auto da Alma (onde é hostilizada pela mentira do Diabo); é ainda por falta de Verdade que entram na barca perdida os condenados do Inferno

\footnotetext{
9 Refiro-me, concretamente, a peças como Mofina Mendes, Feira ou Sibila Cassandra, qualquer delas concluída com o Presépio. E é manifesto que, para além da circunstância, esse desfecho obriga à reorientação da leitura dos desconcertos anteriormente encenados.
} 
e do Purgatório (muitos deles mentirosos, lisongeadores ou alienados). Em contrapartida, foi por terem reconhecido a Verdade, in extremis, que os grandes são tocados por um gesto de Misericórdia na Barca da Glória. É por se proclamar amante da Verdade que o pastor Gil, que no Natal de 1502 se disfarça de Gil Vicente, cunhou a sua imagem perante a Corte régia, declarando-se disposto a afastar-se dos ruídos do mundo e revelando-se capaz de se destacar dos companheiros, justamente para decifrar os mistérios do Presépio ${ }^{10}$. Por último, é por ter proclamado a Verdade que o Filósofo de Floresta de Enganos (derradeira peça do autor, representada em Évora, em 1536) se queixa de ter sido metido "en cárcel muy tenebloso", vendo-se depois amarrado a um parvo sensitivo, que o humilha e o impede de continuar a exprimir-se em público. E isto apenas porque na senda nobre dos filósofos da Antiguidade, não hesitou em proclamar a Verdade.

\section{A teatralidade}

Mas os efeitos que resultavam da presença desta personagem singular não são apenas de caráter semântico. Falo também de efeitos teatrais do maior alcance. Concentrando numa só figura a mensagem de todo o auto, o dramaturgo obtém um outro efeito, ainda inesperado: reforça a teatralidade de todas as outras personagens. Notemos, desde logo, que o auto pressupõe música, para cadenciar as cenas e para servir de emblema a alguns romeiros. E existem, depois, fartos elementos de puro teatro, que estão para além das palavras pronunciadas: o parvo, desastrado guardador de porcos, é assinalado pela distração, não entendendo, muitas vezes, o sentido do que lhe é dito e suscitando no espetador uma reação de contínua ambiguidade; por sua vez, o Vilão Janafonso não vale apenas pela sua representatividade social, convertendo-se, de facto, no mais festivo e paródico vilão de Gil Vicente, tanto pelo que diz como pelo que sugere; o mesmo sucede com a grotesca Filipa Pimenta que, dando como perdido o tempo em que criou o Parvo (seu filho), procura agora recuperar o fogo do amor,

10 Sobre o significado particular desta personagem no Auto Pastoril Castellano e na obra vicentina, em geral, vejam-se Reckert e Cardoso Bernardes (2004/05). 
num registo obsessivo que, para além da representação convencional da velha ensandecida por amor, faz dela mais uma das muitas figuras da irrazoabilidade que abundam no teatro vicentino ${ }^{11}$. Mas o que mais importa sublinhar é que, independentemente da relação que qualquer uma destas personagens mantém com outras do vasto friso vicentino, salta à vista que, tal como comparecem neste auto, elas se revelam menos presas à retórica da mensagem, mais soltas e genuínas; dir-se-ia que, por via desse mesmos efeitos, as personagens se inscrevem num grau de teatralidade mais acentuado do que aquele a que estamos habituados na Compilação.

\section{Uma outra hipótese}

Nada do que disse até aqui coloca em causa as duas razões já aduzidas para justificar a não inclusão do Auto da Festa na Compilação de 1562 e de 1586 e para o seu subsequente esquecimento. Ainda assim, julgo legítimo propor uma terceira hipótese de explicação. Não se trata de excluir nenhuma das que se encontram em apreço. A hipótese que agora avanço destina-se sobretudo a emparceirar com elas: tal como o conhecemos desde 1906, o Auto da Festa constitui matéria teatral não trabalhada pelo autor para figurar no livro e cancioneiro que viria depois a imprimir-se, recolhendo a generalidade da sua produção. Muito provavelmente, o trajeto normal da atividade vicentina implicava diferentes fases: antes de tudo, vinha a invenção teatral, que era, muitas vezes, feita sob o signo da urgência; só depois vinha o tratamento literário desse mesmo material, compreendendo dois parâmetros: a necessidade do aperfeiçoamento técnico-formal propriamente dito, com ganhos retórico-expressivos e perda eventual de alguma teatralidade ${ }^{12}$ e a integração no macrotexto que é, de facto, o Livro das Obras.

11 Como é sabido, a sátira à irrazoabilidade constitui um dos traços mais fortes do teatro vicentino. Para um levantamento dos diferentes focos satíricos no corpus vicentino, veja-se o meu Sátira e Lirismo..., pp. 303 e ss.

12 São essas também as conclusões que podem extrair-se da comparação entre a generalidade dos textos que figuram, ao mesmo tempo, na Compilação e fora dela: Maria Parda, Histórias de Deus, Ressurreição, Barca do Inferno e, sobretudo, Inês Pereira. 
Estou persuadido de que, antes ou depois de Gil Vicente morrer, o Auto da Festa foi teatro. Por uma ou outra razão, assim ficou, não se tendo chegado a cumprir sob o ponto de vista retórico-literário. Não se verificou designadamente o apuramento de alguns aspectos formais nem a sua integração no referido macrotexto, de modo a relacionar-se com os outros autos que aí figuram. Atente-se, de resto, no facto de a peça ter sido impressa sem "Prólogo" ou "Argumento" que, tantas vezes, em si mesmos, constituem um processo para facilitar o reconhecimento genológico, para além de representarem uma forma de estabelecer nexos com outros autos que figuram no Livro. Reconheçamos, aliás, que esta última tarefa não era fácil de cumprir, tantos são os motivos e as personagens que era necessário afeiçoar para que não parecessem repetidos.

Tal como hoje a podemos ler, a peça oferece um outro tipo de interesse: constitui um vestígio revelador da muita matéria que Gil Vicente guardava na sua prodigiosa oficina. Ao que tudo indica, essa oficina não devia diferir muito de outras em que se pode encontrar matéria-prima por utilizar misturada com vestígios de materiais pontualmente aproveitados e logo desmontados por conveniências de vário tipo. Uma oficina mental e material, que se imagina atulhada de elementos dispersos (fórmulas, personagens, tópicos); de outros materiais, quase a ganhar forma orgânica. Nessa oficina, podem finalmente encontrar-se componentes que, tendo já servido para determinados fins, aguardavam reaproveitamento. E, como bem sabem todos os que lidam com o sortilégio das letras e do pensamento, esse tipo de material pode constituir tanto uma oportunidade e uma reserva de conforto como um martírio moral ou mesmo uma frustração. Constitui, muitas vezes, a base de um trabalho sempre projetado e sempre adiado...

Por mim, estou hoje persuadido de que, à morte de Gil Vicente, o Auto da Festa se encontrava nesta última prateleira: a dos materiais que, tendo servido para uma determinada circunstância, aguardava reutilização adequada. Dessa mesma prateleira saiu depois para uma edição avulsa, que acabou recolhida na dita miscelânea que o Conde de Sabugosa viria a herdar. Tudo isto comprova, afinal, a existência de dois dados importantes: um que já se conhecia e um outro mais teórico e porventura menos considerado: já se sabia nomeadamente que o dramaturgo trabalhava por fases e por tentativas (para desgosto daqueles que, desde a sua descoberta romântica, sempre viram nele um "repentista", 
Gil Vicente só poderia ter trabalhado desta forma ${ }^{13}$. Mas esta pequena visita à rica oficina do dramaturgo de D. Leonor prova ainda outra coisa: que, no seu tempo, existia uma consciência clara das diferenças de registo entre o texto (editado ou não) que servia diretamente o espectáculo e aquele outro que se podia dar depois a ler, em forma de livro ${ }^{14}$. Muito provavelmente, os textos que figuram na Copilaçam resultaram de matrizes teatrais entretanto desaparecidas. O Auto da Festa não chegou a esta última fase. Porque isso representaria um esforço demasiado árduo, porque o resultado final poderia não agradar a D. João III, para quem Gil Vicente trabalhou ao longo de 15 anos consecutivos e para quem, no final dos seus dias, com pena de sua velhice, o dramaturgo chegou a reunir as suas obras. Ou ainda (quem sabe?) porque esta peça nasceu de um parênteses de circunstâncias amargas, fora da corte régia. Tão fora que não era depois possível submetê-la ao verniz retórico e moral que, apesar de tudo, recobre a generalidade do Cancioneiro que, em Setembro de 1562, viria a sair dos prelos de João Álvares, "impressor d'el rei nosso senhor".

13 Em trabalho recente, centrado no Triunfo do Inverno e do Verão e no Auto dos Quatro Tempos, Isabel Almeida aponta justamente para um procedimento congénere que carateriza desta forma: "o expedito e amiudado recurso a materiais disponíveis, a texto feito, por mão alheia ou pela sua, respeitando um princípio de economia e uma preocupação de eficácia" (p. 251)

14 Entre nós, Osório Mateus foi quem mais chamou a atenção para a necessidade de reparar nesta diferença. Fê-lo repetidamente ao longo dos seus estudos vicentinos e chegou a escrever um artigo diretamente sobre o assunto. 


\section{BIBLIOGRAFIA}

\section{Ativa}

VICENTE, Gil, (1906), Auto da Festa. Obra desconhecida com uma explicação prévia pelo Conde de Sabugosa, Lisboa, Imprensa Nacional.

As Obras de Gil Vicente (Direcção Científica de José Camões), (2002), Lisboa, INCM, (reprodução fac-similada no vol. IV, pp. 675-690 e transcrição no Vol. II, pp. 655-685).

\section{Passiva}

ALMEIDA, Isabel, (2011), "Bis Repentita Placent. Para uma releitura do Triunfo do Inverno e do Verão", in Por s'entender bem a letra. Homenagem a Stephen Reckert (org. de Manuel Calderón, José Camões e José Pedro Sousa), Lisboa, INCM, pp. 251-259.

BERNARDES, José Augusto Cardoso, (2004), Sátira e Lirismo no Teatro de Gil Vicente, Lisboa, INCM.

(2004/2005), "A Copilaçam de todalas obras: o livro e o projecto identitário de Gil Vicente", in Diacrítica. Ciências da Literatura, 18-19 pp. 179-198.

BONFIM, Eneida do Rego Monteiro, (2003), "Uma leitura dos autos de Gil Vicente: o Auto da Festa", in Semear, 8 pp., 193-2011.

CAMÕES, José, (1992), Festa, Quimera, Lisboa.

MATEUS, J. Osório, (1993), Livro das Obras, Lisboa, Quimera.

__, (s/d), "Teatro e Literatura" in De teatro e outras escritas, Lisboa Quimera, pp. 212-218.

MELLO MOSER, Fernando de, (2004), "Gil Vicente da Meia Idade ao Renascimento", in Discurso Inacabado, Lisboa, Fundação Calouste Gulbenkian, pp. 15-154.

PRATT, Óscar de, (1970), "Ainda o Auto da Festa", in Gil Vicente. Notas e Comentários, Lisboa, Livraria Clássica Editora, pp. 231-238.

RECKERT, Stephen, (2002), "Gil Terrón lletrudo está", in Leituras. Revista da Biblioteca Nacional, 11 (Outono), pp. 15-33. 